\title{
Targeting Energy Metabolism to Overcome Therapeutic Resistance of Glioblastoma and Tumor-associated Edema
}

Biplab Dasgupta ${ }^{1}$ - Yoshihisa Hirota ${ }^{2,3} \bullet Y^{\prime}$ Yuki Fujii ${ }^{2,4} \bullet$ Natsuki Osaka $^{5} \bullet$ Doshun Ito ${ }^{6} \bullet$ David R. Plas ${ }^{7} \bullet$ Atsuo T. Sasaki²,5,7,8

${ }^{1}$ Division of Oncology, Cincinnati Children's Hospital Medical Center, Cincinnati, OH, USA; ${ }^{2}$ Division of Hematology and Oncology, Department of Internal Medicine, University of Cincinnati College of Medicine, Cincinnati, OH, USA; ${ }^{3}$ Department of Bioscience and Engineering, College of Systems Engineering and Science, Shibaura Institute of Technology, Fukasaku, Minuma-ku, Saitama, Japan; ${ }^{4}$ Graduate School of Science, Osaka City University, Sugimoto, Sumiyoshi, Osaka, Japan; ${ }^{5}$ Institute for Advanced Biosciences, Keio University, Tsuruoka, Japan; ${ }^{6}$ Structural Biology Research Center, Institute of Materials Structure Science, High Energy Accelerator Research Organization (KEK), Tsukuba, Ibaraki, Japan; ${ }^{7}$ Department of Cancer Biology, University of Cincinnati College of Medicine, OH, USA; ${ }^{8}$ Department of Neurosurgery, Brain Tumor Center at UC Gardner Neuroscience Institute, Cincinnati, OH, USA

Author for correspondence: Atsuo T. Sasaki, Division of Hematology and Oncology, Department of Internal Medicine, University of Cincinnati College of Medicine, Cincinnati, OH, USA. Email: atsuo.sasaki@uc.edu

Doi: https://doi.org/10.36255/exonpublications.gliomas.2021.chapter7

\begin{abstract}
Glioblastoma remains among the most lethal of human malignancies. The current standard of care prolongs life expectancy about 2 months on average compared to from radiation therapy alone, leading to a median patient survival of 14.6 months. Glioblastoma is heterogenous tumor at various levels, and intrinsically resistance to radiation and chemotherapy. These limits therapeutic
\end{abstract}

In: Gliomas. Debinski W (Editor). Exon Publications, Brisbane, Australia. ISBN: 978-0-6450017-4-7; Doi: https://doi.org/10.36255/exonpublications.gliomas.2021

Copyright: The Authors.

License: This open access article is licenced under Creative Commons Attribution-NonCommercial 4.0 International (CC BY-NC 4.0) https://creativecommons.org/licenses/by-nc/4.0/ 
options for both primary and recurrent tumors. Importantly, glioblastoma progression is often accompanied by cerebral edema, a significant cause of morbidity that influences the clinical course and prognosis of the disease. Immunosuppressive corticosteroids have been the primary treatment for glioblastoma-associated edema. However, the effect is temporary and accompanied by adverse effects due to the action of corticosteroids outside of the targeted area. Research over the past two decades has unveiled a significant role for metabolic reprogramming that confers a survival advantage during gliomagenesis and therapeutic resistance. This chapter introduces the recent discoveries of two energy metabolism pathways: AMP-activated kinase-mediated stress-resilient glioblastoma growth, and Guanosine-5'-triphosphate (GTP)- metabolic reprogramming that renders anabolic growth and radioresistance. We discuss the potential clinical utility of currently available medicine that could target these metabolic pathways to suppress malignant growth of glioblastoma and increase the efficacy of the current glioblastoma therapy.

Keywords: energy metabolism; edema; purine nucleotide metabolism; radioresistance; radiosensitivity

\section{INTRODUCTION}

Gliomas are the most common malignant primary tumors of the central nervous system (1). Glioblastoma (GBM) is the grade IV glioma based on the WHO classification (2), and constitute about $54 \%$ of all gliomas (1). For high-grade gliomas (i.e., WHO grade III and IV), the 5-year survival rate is below $10 \%$, even with aggressive treatment of surgical resection with adjuvant radiation and chemotherapy. Even low-grade glioma (WHO grade II) are ultimately lethal, with a median survival term of $6-8$ years $(3,4)$. Currently, curative treatments are unavailable for glioma.

Radiotherapy is one of the primary treatment modalities (5), constituting a part of the current standard of care (6). However, glioblastomas are intrinsically resistant to radiotherapy (7-15) due to increased ROS resistance mediated by mechanisms not currently understood $(13,14,16-18)$. Radiation therapy yields only marginal improvements in patient survival $(19,20)$, with a recurrence rate of nearly $80 \%$ despite use of high dose radiation $(21,22)$. The current standard of care treatment for glioblastoma includes maximal safe surgical resection followed by adjuvant radiotherapy plus DNA alkylating reagent temozolomide chemotherapy, which prolonged a median patient survival of 14.6 months, from that of 10. 6 months of radiotherapy alone $(19,20)$.

Most glioblastoma patients ( $>60 \%$ ) suffer from glioblastoma-associated cerebral edema that represents a major cause of morbidity in glioblastoma. Patients with cerebral edema experience headaches, seizures, dysphagia, and cognitive and personality changes. The accumulation of fluids increases intracranial pressure, leading to ischemia, herniation, and ultimately death (23). Furthermore, glioblastoma-associated edema influences the clinical course and the prognosis of the disease $(24,25)$. Inflammation and neoangiogenesis, which destroy the integrity of the blood-brain barrier (BBB) causing fluid leakage, are two major causes 
of glioblastoma-associated edema. Immunosuppressive corticosteroids have been the primary treatment for glioblastoma-associated edema since the 1960s. However, the effect is temporary and accompanied by adverse effects due to the systemic effects of corticosteroids (26-28). Importantly, recent studies show that corticosteroids may reduce survival in human glioblastoma patients (26-28) and murine glioblastoma model (29). Vascular endothelial growth factor (VEGF)signaling inhibitor bevacizumab (Avastin) has an anti-edema effect; however, it does not extend patient survival (30-32) and causes adverse events, including hypertension, arterial and venous thrombosis, intracerebral hemorrhage, and slow wound healing $(30,33-35)$. Our recent studies about energy metabolism in GBM implicate the potential of repurposing existing drugs that could lead to the resensitization of glioblastoma patients to radiation therapy or/and suppress glioblastoma-associated edema while inhibiting tumor growth.

In the past decades, extensive research has uncovered genetic mutations (36-43), transcriptional changes (44-51), and reconfiguration of signaling pathways $(49,52-55)$ in glioblastoma pathogenesis. These studies reveal that glioma is highly heterogeneous, enabling multiple robust transcriptional, signaling, and metabolic programs that mediate apoptosis resistance of glioblastoma during tumorigenesis and confer therapeutic resistance. Importantly, even before the era of molecular biology, metabolic changes in glioma have been noted $(55,56)$. In the 1940s, a series of biochemical analyses conducted on human brain tumors, including glioma, revealed significant elevations of lipids in these tumors, particularly glioma $(56,57)$. More recent studies with advanced molecular methods and high-sensitivity mass spectrometry-based analytical methods have clarified a mechanistic basis of the metabolic changes to increase lipid synthesis and accumulation of lipid droplets in glioma and glioma stem cells, contributing to the malignant growth of gliomas (58-61). The changes in nucleotide metabolism in glioma was denoted in the early 1950s (62), which is in part confirmed by enzymatic analysis that shows dramatic suppression of salvage GTP biosynthetic enzymes in glioma in 1994 (63), further followed by recent molecular studies $(64,65)$. These metabolic changes provide the building blocks for major cellular constituents-proteins, lipids, and nucleotides-to match the high metabolic demand of rapidly growing glioma cells (66). Notably, more recent studies, including ours, have shown critical metabolic pathways that induce coordinated anabolic growth through multiple mechanisms (67-70).

This chapter introduces two energy metabolism-related signaling pathwaysAMP-activated kinase (AMPK) and guanosine-5'-triphosphate (GTP) metabolismthat are activated in glioma. Then, we discuss the possible therapeutic benefits of targeting these energy metabolisms to suppress glioma progression and sensitize glioma for the current therapeutics in particular radiotherapy.

\section{EMERGING ROLES OF ENERGY METABOLISM IN GLIOBLASTOMA AND THERAPEUTIC TARGETING}

In part, glioblastoma malignancy stems from its increased resistance to stress conditions during gliomagenesis, which is positively associated with therapeutic 
resistance, including radiation therapy (7-15). Until recently, whether and how cellular metabolism is integrated into the process of glioma formation, progression and stress resilient growth is understudied. This section introduces emerging roles of energy metabolism in gliomagenesis and its potential clinical utility as a new therapeutic target for glioblastoma.

\section{ATP energy sensor, AMPK, is critical to overcoming stresses during gliomagenesis}

Stress is central to tumor evolution (71). The success of tumor cells in the hostile tumor milieu depends on how well tumor cells activate stress management pathways. Metabolic stress in solid tumors like glioblastoma poses a formidable challenge for tumor cell survival. These stresses include nutrient, hypoxic, $\mathrm{pH}$, and oxidative stress in addition to therapy-induced xenobiotic stress (71-73). Metabolic stress is often caused by energy stress, which reduces the cellular ATP to AMP ratio and activates the energy sensor AMPK $(74,75)$ (Figure 1). Once activated, AMPK augments energy-generating reactions such as glycolysis and mitochondrial oxidative phosphorylation of glucose and fatty acids $(74,75)$.

Because AMPK is part of the liver kinase Bl (LKB1) tumor suppressor pathway and turns off major biosynthetic reactions such as lipid and protein synthesis-processes that are key to tumor cell growth and proliferation-it was long

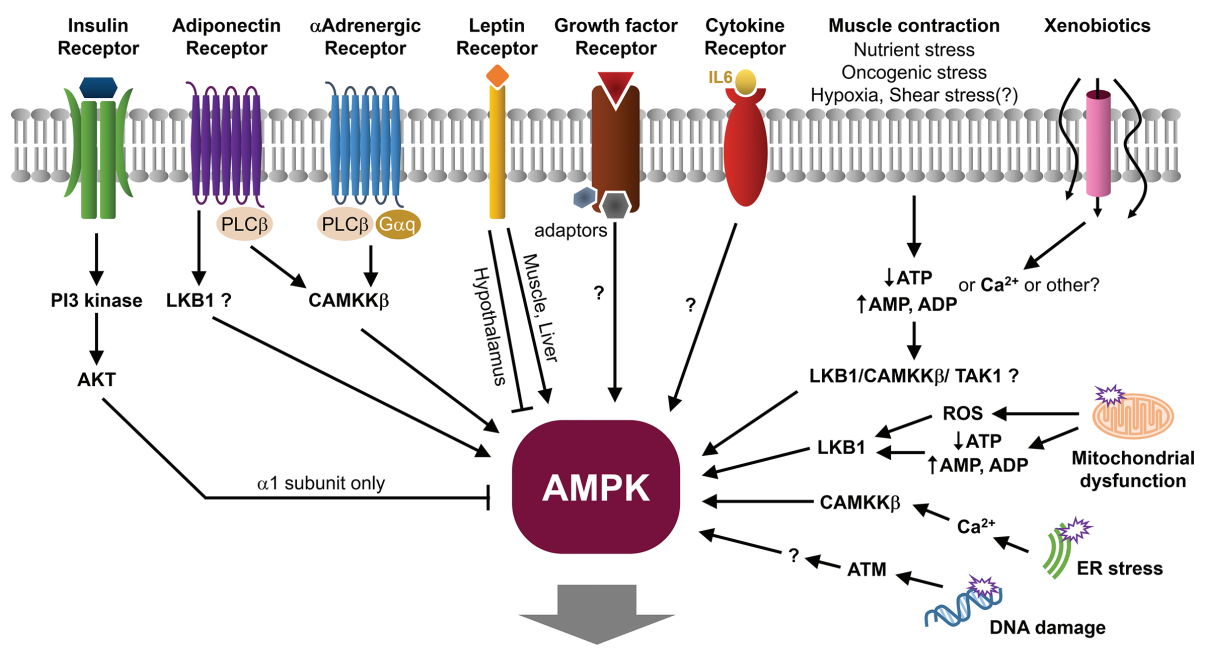

Stress resistant GBM growth and survival

Figure 1. Activation of AMPK pathway has glioblastoma cells to be high stress resistant. AMPK receives many intra- and extra-cellular signals as a part of LKB1, CAMKKb, and other pathways. Activated AMPK leads to high stress resistance of GBM cells and supports their growth and survival. 
believed that AMPK had a net suppressive role in tumorigenesis, including glioblastoma (76). However, AMPK-deficient transformed cells under tumor-like hypoxic conditions have a growth disadvantage in vivo (77). Taking an orthogonal approach, we determined that AMPK activity is abundant in all high-grade gliomas regardless of the genetic background of the tumors $(78,79)$. We showed that through transcriptional control of glioblastoma bioenergetics AMPK is required for optimal growth and survival of glioblastoma (79). Studies from other laboratories also concluded a role for AMPK in glioma pathogenesis. In an $\mathrm{N}$-ethyl-N-nitrosourea-induced rat model of brain tumors, high AMPK activity was reported from the early hyperplastic lesions to the fully formed tumors (80). In a mouse model of astrocytoma driven by mutant HRas and Pten deletion, AMPK was necessary to maintain astrocytoma proliferation and survival (81) and lipoprotein internalization (82). The inhibitory role of AMPK on major biosynthetic processes that are required for cell growth and division appears paradoxical to the presence of high levels of active AMPK in glioblastoma and other solid tumors. However, as the tumor grows in volume, a plethora of tumorspecific stress builds up. This includes oncogenic stress, nutrient and oxygen stress due to fluctuating nutrients and oxygen levels and malformed neovasculature, and $\mathrm{pH}$ stress caused by the harsh acidic environment. These stresses reprogram tumor metabolism that allows tumor cells to survive and thrive in this stressful tumor microenvironment. Although the mechanisms are not fully clear, active AMPK may support this altered tumor metabolism and tumor cell survival (74).

\section{A potential of AMPK targeting to enhance the efficacy of radiation therapy}

One of the important consequences of AMPK activation is the upregulation of autophagy. Importantly, the enhanced autophagy contributes to radioresistance in glioblastoma and many other tumors (83-86). A priori, AMPK activation constitutes a key element of glioblastoma radioresistance $(87,88)$. Up to now, agents that indirectly activate AMPK were used to suppress tumor cell growth, including glioma growth (89-91). Notable agents include the antidiabetic biguanide drugs (metformin and phenformin) and the de novo purine synthesis pathway metabolite AICAR. Biguanides inhibit mitochondrial complex I and cause energy stress, while AICAR metabolizes to ZMP, which mimics AMP-each process activating AMPK $(92,93)$. Importantly, metformin has been shown to increase radiosensitivity (94-96). Although this may appear paradoxical, studies from our laboratory have shown that the anti-glioma effects of AICAR and biguanides are not only AMPK-independent but, in fact, AMPK-silenced glioma cells lose metabolic plasticity and become more vulnerable to the cytotoxic effects of AICAR and biguanides (78). This loss of metabolic plasticity of AMPK pathway deficient cells is likely conserved across other tumor types since LKB1 null lung cancer cells are also hypersensitive to biguanides (97). Together, results from preclinical and clinical studies illuminate a unique opportunity to use biguanides in clinical trials in combination with AMPK inhibitors, which are currently under development in our laboratory. The expectation is that this combination will likely synergize to overcome the radioresistance of glioblastoma. 


\section{GTP METABOLIC REPROGRAMMING PROMOTES GLIOBLASTOMA MALIGNANCY}

ATP and GTP are involved in many cellular functions, including DNA and RNA building blocks, energy sources, enzymatic cofactors in metabolic pathways, and components of signal transduction. There are two pathways to produce GTP. De novo GTP synthesis involves a multi-step, high nutrient and energy-consuming pathway. Glucose is converted to GTP through 19 enzymatic steps that use a glycine molecule, an aspartate molecule, 3 glutamines, $2 \mathrm{~N}^{10}$-formyl-THF, and 10 ATP. In contrast, the salvage pathway is an energy-efficient process in which a nucleoside (inosine, guanosine) and a nucleobase (hypoxanthine, guanine) are recycled to produce a GTP $(98,99)$ (Figure 2$)$. As a result, the use of the salvage pathway is heavily favored in adult tissues, particularly in the adult brain (100-102). Importantly, many tumors increase GTP levels more than the other ribonucleotides, including glioblastoma $(65,103)$. However, how and why tumors alter GTP metabolism for their malignant growth has not previously been explored.

To that end, we have discovered a lipid kinase PI5P4K $\beta$ as an intracellular GTP sensor regulating the metabolism and the tumorigenic process in accordance with cellular GTP energy levels $(104,105)$. Also, a recent publication of ours showed that GTP biosynthesis is significantly upregulated in glioblastoma by IMP dehydrogenase isozyme-2 (IMPDH2), which promotes enhanced ribosome biogenesis and tRNA synthesis, cooperating malignant glioblastoma growth in vitro and in vivo while normal brain cells operate without this GTP biosynthetic pathway (65). IMPDH2 mRNA expression is not significantly correlated with IMPDH2 protein levels, suggesting posttranscriptional regulation and therefore the importance of immunohistochemical analysis to evaluate the IMPDH2 levels. Importantly, increased IMPHD2 is correlated with poor survival of glioma patients regardless of IDH mutational status (65). Mechanistically, IMPDH2 upregulation promotes de novo GTP biosynthesis for ribosome biogenesis and tRNA synthesis, leading to nucleolar enlargement and malignant growth of glioblastoma (Figure 3). Inhibition of IMPDH2 decreases nucleolar size and significantly suppresses glioblastoma growth in vitro and vivo (65). The significance of IMPDH2 in glioblastoma and multiple cancers is also supported by other studies $(68,99,106)$. Together, these studies illuminate the potential of targeting IMPDH-dependent GTP synthesis as a treatment for glioma. Importantly, there are FDA-approved inhibitors for IMPDH, including MPA and MMF (Figure 3) (106).

\section{Targeting the GTP metabolic reprogramming to increase the efficacy of radiation therapy}

Nucleotides are essential factors for genome stability and DNA repair (107-110). Importantly, studies of radioresistant bacteria, Micrococcus luteus, suggest that the GTP-metabolism is associated with radioresistance $(111,112)$. In cancer cells, IMPDH inhibition causes DNA lesions (113) and suppresses DNA damage-repair induced by radiation $(114,115)$. Radioresistant glioblastoma cell lines and glioblastoma-stem-like cells are capable of increasing guanylate levels in response to radiation (116). MPA/MMF treatment prevents this, leading to decreased DNA 


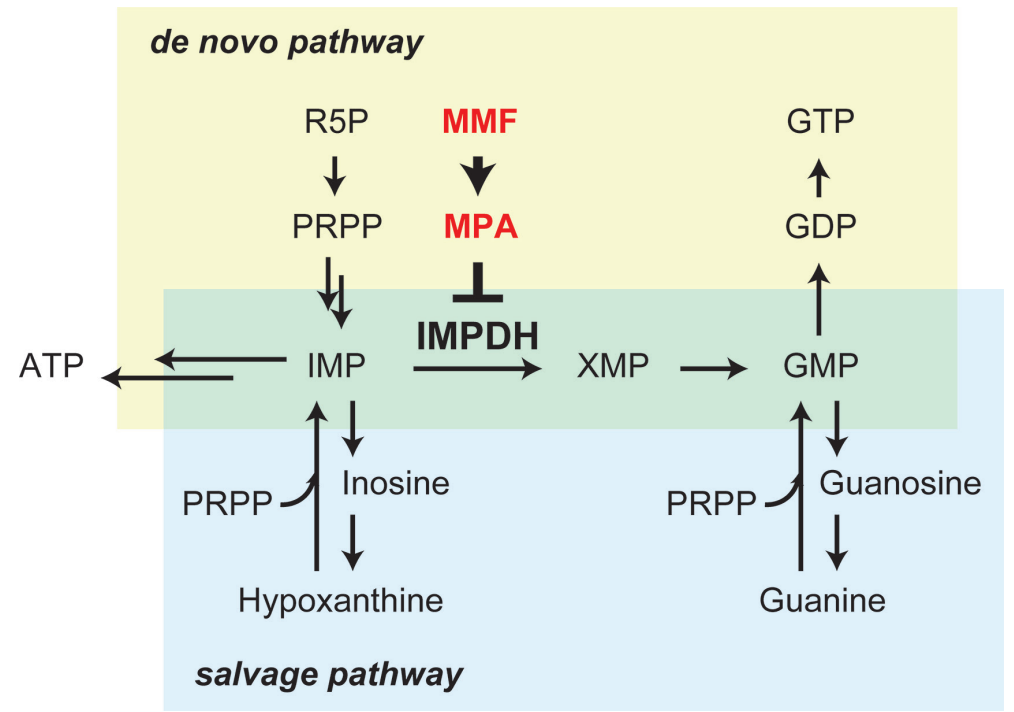

Figure 2. Two types of GTP synthesis pathways. GTP synthesis is controlled by two pathways. A sugar, phosphoribosyl diphosphate (PRPP), is made by ribose-5-phosphate (R5P) involved in pentose phosphate pathway. In de novo pathway, IMP is generated from PRPP through high nutrient and energy consuming reactions. On the other hand, salvage pathway produces a new IMP or GMP by directly connecting a sugar (PRPP) and a nucleobase (hypoxanthine or guanine). These nucleobases come from recycled IMP or GMP metabolites (inosine or guanosine). This economical pathway is favored in adult tissues. IMP dehydrogenase (IMPDH) oxidizes IMP to XMP. IMPDH is involved in the first step of guanine nucleotide synthesis and plays important roles in proliferation, cellular homeostasis, and also tumors facilitation including GBM. IMPDH activity is strongly inhibited by mycophenolate mofetil (MMF), which is a precursor of mycophenolic acid (MPA) and uses as prodrug of immunosuppressant. ATP, adenosine triphosphate; GDP, guanosine diphosphate; GMP, guanosine monophosphate; GTP, guanosine triphosphate; IMP, inosine monophosphate; IMPDH, IMP dehydrogenase; MMF, mycophenolate mofetil; MPA, mycophenolic acid; PRPP, phosphoribosyl diphosphate; R5P, ribose-5-phosphate; XMP, xanthine monophosphate.

repair and clonogenic glioblastoma growth, thereby extending survival in an orthotopic PDX-glioblastoma model (116). In osteosarcoma U2OS cells, IMPDH2 overexpression increases radioresistance, while IMPDH2 knock-down increases radiosensitivity (117). These results suggest the previously unrecognized role of IMPDH2 in radioresistance (Figure 3). Importantly, Phase 0/1 Trial (NCT04477200) looking at the effects of MMF with radiation has been initiated to define the maximum tolerated dose of MMF when administered with radiation, in patients with recurrent glioblastoma or recurrent gliosarcoma. As of December 2020, our multidisciplinary group at the University of Cincinnati is in the preparation of a new MMF trial for glioblastoma treatment from a different angle, which is to treat GBM-associated edema by MMF. Collectively, repurposing IMPDH inhibitors has an important potential for new glioblastoma therapeutics and should be further studied to develop more effective, optimally designed therapeutics for clinical utilization to overcome radiation resistance and complications associated with glioblastoma. 


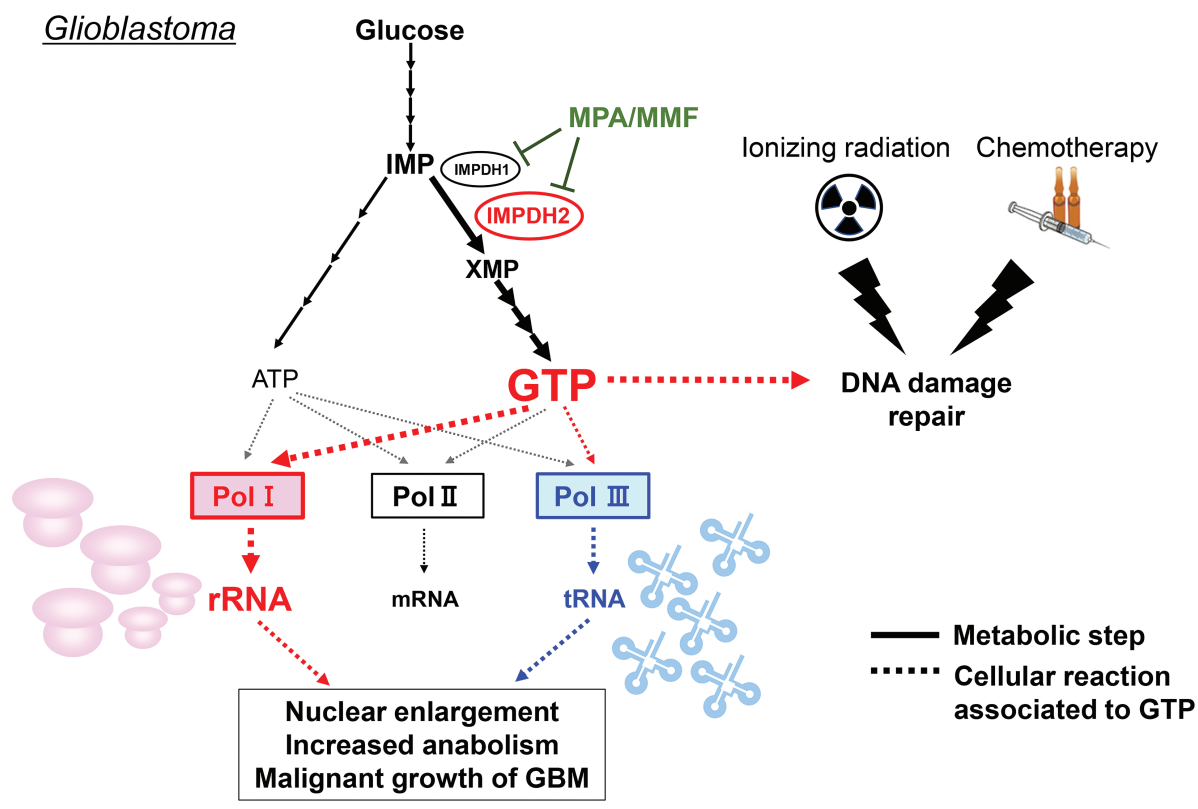

Figure 3. Upregulation of de novo GTP biosynthesis by IMPDH2 generates aberrant phenotype of Glioblastoma. In Glioblastoma (GBM), de novo GTP biosynthesis is upregulated by IMPDH2. Increasing GTP levels promotes rRNA and tRNA synthesis through transcription by RNA polymerase I (Pol I) and RNA polymerase Ш (Pol Ш) respectively. Upregulation of r/tRNA synthesis cause nuclear enlargement, increased anabolism, and malignant growth. Moreover, elevated GTP promotes DNA damage repair for radioresistance in GBM. MPA and MMF, the inhibitor for IMPDH, block both r/tRNA synthesis. Moreover, decrease in GTP levels by MPA and MMF indirectly inhibits GTP-associated DNA damage repair. Solid line indicates the metabolic step and dotted line indicates the cellular reactions associated to GTP.

\section{A possible utility of the immunosuppressive effect of MMF to ameliorate glioblastoma-associated edema}

Since MMF has been used as a potent immunosuppressor for tissue transplanted patients and autoimmune disease, a potential caveat of MMF or any IMPDH inhibitor is that it may limit the use of an upfront glioblastoma setting. However, we propose that MMF's use may be beneficial in some situations, particularly glioblastoma-associated edema treatment, based on the following evidence:

(i) MMF suppresses inflammation and stroke-associated edema: MMF is used globally for organ transplanted patients and possesses greater potency for the IMPDH2 isozyme (118). Importantly, MMF inhibits activation of microglia and astrocytes (119) and monocyte recruitment to endothelial cells (120, 121). In the LPS-stimulated BALB/c mouse neuroinflammation model, MMF treatment suppressed the expression of pro-inflammatory proteins (for example, iNOS, COX-2, TNF $\alpha$, IL-1 $\beta$, IL-6) (122). Furthermore, MMF treatment suppressed cerebral edema in stroke-prone spontaneous hypertensive rats (SHR-A3) (123). 
(ii) MMF suppresses neoangiogenesis: Several reports indicate a critical link between IMPDH2 and neoangiogenesis. Two studies using zebrafish embryos show that IMPDH2, but not IMPDH1, is highly expressed at the sites of new blood vessels, and MPA treatment suppresses angiogenesis $(124,125)$. MPA treatment suppressed angiogenesis of human endothelial cells $(126,127)$. Oral administration of MMF significantly suppressed in vivo angiogenesis induced by melanoma (128), pancreatic cancer $(129,130)$ and U87MG glioma (127). Importantly, our preliminary studies using hCMEC/D3 cells, widely used as BBB models (131137), show that MPA treatment does not disrupt the integrity of BBB.

Thus, MMF treatment has a high potential to suppress neoangiogenesis while maintaining BBB integrity. Currently, our multidisciplinary group at the University of Cincinnati is actively pursuing research to clarify the utility of MMF for glioblastoma edema treatment.

\section{CONCLUSION}

Despite the advances in general cancer treatment, glioblastoma remains among the most lethal of human malignancies. Even with aggressive multimodal radiation and chemotherapy after surgery, radiation therapy yielded marginal improvements in patient survival $(19,20)$ due to the radioresistant nature of glioblastoma. It is crucial to develop more effective therapeutics to improve the prognosis of the average patient with a glioblastoma and identify glioblastoma vulnerabilities for new potential targets and test the setting in clinically relevant glioblastoma animal models. In this chapter, we have introduced new potential targets for glioblastoma therapy, which are expected to suppress glioblastoma regardless of mutational status and increase the efficacy of the current therapeutic regimen when combined. For the next stage, it is crucial to further investigate the drugs targeting AMPK and IMPDH on the survival, therapeutic resistance, and edema formation of immunocompetent glioblastoma mouse models, and assess pharmacodynamics and identify PD markers. It is also imperative to study the combinations of these drugs with radiation therapy, including upfront proton beam therapy as introduced in the following chapter.

Acknowledgment: This work has been supported by the MTP UC-Brain Tumor Center grant, Ohio Cancer Research, B*Cured, JSPS KAKENHI (20H03165), R21NS100077, and R01NS089815 (A.T.S.), and the Fund for the Promotion of Joint International Research (Fostering Joint International Research (A)) from the JSPS, 18KK0455 (Y.H.). This work was supported in part by research funds from the Yamagata prefectural government and the City of Tsuruoka.

Conflict of interest: The authors declare no potential conflicts of interest with respect to research, authorship, and/or publication of this chapter.

Copyright and Permission Statement: The authors confirm that the materials included in this chapter do not violate copyright laws. Where relevant, appropriate permissions have been obtained from the original copyright holder(s). All original sources have been appropriately acknowledged and/or referenced. 


\section{REFERENCES}

1. Ostrom QT, Patil N, Cioffi G, Waite K, Kruchko C, Barnholtz-Sloan JS. CBTRUS Statistical Report: Primary Brain and Other Central Nervous System Tumors Diagnosed in the United States in 20132017. Neuro-oncology. 2020;22(12 Suppl 2):ivl-iv96. https://doi.org/10.1093/neuonc/noaa200

2. Louis DN, Perry A, Reifenberger G, Deimling von A, Figarella-Branger D, Cavenee WK, et al. The 2016 World Health Organization Classification of Tumors of the Central Nervous System: a summary. Acta Neuropathol. 2016;131(6):803-20. https://doi.org/10.1007/s00401-016-1545-1

3. Walker DG, Kaye AH. Low grade glial neoplasms. J Clin Neurosci. 2003;10(1):1-13. https://doi. org/10.1016/S0967-5868(02)00261-8

4. Claus EB, Black PM. Survival rates and patterns of care for patients diagnosed with supratentorial low-grade gliomas. Cancer. 2006;106(6):1358-63. https://doi.org/10.1002/cncr.21733

5. Abshire D, Lang MK. The Evolution of Radiation Therapy in Treating Cancer. Semin Oncol Nurs. 2018;34(2):151-7. https://doi.org/10.1016/j.soncn.2018.03.006

6. Sulman EP, Ismaila N, Armstrong TS, Tsien C, Batchelor TT, Cloughesy T, et al. Radiation Therapy for Glioblastoma: American Society of Clinical Oncology Clinical Practice Guideline Endorsement of the American Society for Radiation Oncology Guideline. J Oncol Pract. 2017;35(3):361-69. https://doi. org/10.1200/JCO.2016.70.7562

7. Laperriere N, Zuraw L, Cairncross G. Cancer Care Ontario Practice Guidelines Initiative NeuroOncology Disease Site Group. Radiotherapy for newly diagnosed malignant glioma in adults: a systematic review. Radiother Oncol. 2002;64(3):259-73. https://doi.org/10.1016/S0167-8140(02)00078-6

8. Grossman SA, Batara JF. Current management of glioblastoma multiforme. Semin Oncol. 2004; 31(5):635-44. https://doi.org/10.1053/j.seminoncol.2004.07.005

9. Furnari FB, Fenton T, Bachoo RM, Mukasa A, Stommel JM, Stegh A, et al. Malignant astrocytic glioma: genetics, biology, and paths to treatment. Genes Dev. 2007;21(21):2683-710. https://doi. org/10.1101/gad.1596707

10. Chalmers AJ. Radioresistant glioma stem cells--therapeutic obstacle or promising target? DNA Repair. 2007;6(9):1391-4. https://doi.org/10.1016/j.dnarep.2007.03.019

11. Wang J, Wakeman TP, Lathia JD, Hjelmeland AB, Wang X-F, White RR, et al. Notch promotes radioresistance of glioma stem cells. Stem Cells. 2010;28(1):17-28. https://doi.org/10.1002/stem.261

12. Hatanpaa KJ, Burma S, Zhao D, Habib AA. Epidermal growth factor receptor in glioma: signal transduction, neuropathology, imaging, and radioresistance. Neoplasia. 2010;12(9):675-84. https://doi. org/10.1593/neo.10688

13. Bao S, Wu Q, McLendon RE, Hao Y, Shi Q, Hjelmeland AB, et al. Glioma stem cells promote radioresistance by preferential activation of the DNA damage response. Nature. 2006;444(7120):756-60. https://doi.org/10.1038/nature05236

14. Matlaf L. Reactive oxygen species-mediated therapeutic response and resistance in glioblastoma. Cell Death Dis. 2015;6(1):el601-1. https://doi.org/10.1038/cddis.2014.566

15. Han X, Xue X, Zhou H, Zhang G. A molecular view of the radioresistance of gliomas. Oncotarget. 2017;8(59):100931-41. https://doi.org/10.18632/oncotarget.21753

16. Rinaldi M, Caffo M, Minutoli L, Marini H, Abbritti RV, Squadrito F, et al. ROS and Brain Gliomas: An Overview of Potential and Innovative Therapeutic Strategies. Int J Mol Sci. 2016;17(6):984. https:// doi.org/10.3390/ijms17060984

17. Salazar-Ramiro A, Ramírez-Ortega D, Pérez de la Cruz V, Hérnandez-Pedro NY, González-Esquivel DF, Sotelo J, et al. Role of Redox Status in Development of Glioblastoma. Front Immunol. 2016;7(2): 157-15. https://doi.org/10.3389/fimmu.2016.00156

18. Polewski MD, Reveron-Thornton RF, Cherryholmes GA, Marinov GK, Aboody KS. SLC7A11Overexpression in Glioblastoma Is Associated with Increased Cancer Stem Cell-Like Properties. Stem Cells Dev. 2017;26(17):1236-46. https://doi.org/10.1089/scd.2017.0123

19. Stupp R, Hegi ME, Mason WP, van den Bent MJ, Taphoorn MJ, Janzer RC, et al. Effects of radiotherapy with concomitant and adjuvant temozolomide versus radiotherapy alone on survival in glioblastoma in a randomised phase III study: 5-year analysis of the EORTC-NCIC trial. Lancet Oncol. 2009;10(5):459-66. https://doi.org/10.1016/S1470-2045(09)70025-7 
20. Stupp R, Mason WP, Van Den Bent MJ, Weller M, Fisher B, Taphoorn MJB, et al. Radiotherapy plus concomitant and adjuvant temozolomide for glioblastoma. N Engl J Med. 2005;352(10):987-96. https://doi.org/10.1056/NEJMoa043330

21. Brandes AA, Tosoni A, Franceschi E, Sotti G, Frezza G, Amistà P, et al. Recurrence pattern after temozolomide concomitant with and adjuvant to radiotherapy in newly diagnosed patients with glioblastoma: correlation With MGMT promoter methylation status. J Clin Oncol. 2009;27(8):1275-9. https://doi.org/10.1200/JCO.2008.19.4969

22. Gebhardt BJ, Dobelbower MC, Ennis WH, Bag AK, Markert JM, Fiveash JB. Patterns of failure for glioblastoma multiforme following limited-margin radiation and concurrent temozolomide. Radiat Oncol. 2014;9(1):130. https://doi.org/10.1186/1748-717X-9-130

23. Papadopoulos MC, Saadoun S, Binder DK, Manley GT, Krishna S, Verkman AS. Molecular mechanisms of brain tumor edema. Neurosci. 2004;129(4):1011-20. https://doi.org/10.1016/j. neuroscience.2004.05.044

24. Stummer W. Mechanisms of tumor-related brain edema. J Neurosurg. 2007;22(5):E8-7. https://doi. org/10.3171/foc.2007.22.5.9

25. Lin L, Xue Y, Duan Q, Sun B, Lin H, Huang X, et al. The role of cerebral blood flow gradient in peritumoral edema for differentiation of glioblastomas from solitary metastatic lesions. Oncotarget. 2016;7(42):69051-9. https://doi.org/10.18632/oncotarget.12053

26. Wu C-X, Lin G-S, Lin Z-X, Zhang J-D, Liu S-Y, Zhou C-F. Peritumoral edema shown by MRI predicts poor clinical outcome in glioblastoma. World J Surg Oncol. 2015;13(1):97-9. https://doi. org/10.1186/s12957-015-0496-7

27. Schiff D, Lee EQ, Nayak L, Norden AD, Reardon DA, Wen PY. Medical management of brain tumors and the sequelae of treatment. Neuro-Oncol. 2015;17(4):488-504. https://doi.org/10.1093/neuonc/ nou304

28. Arvold ND, Armstrong TS, Warren KE, Chang SM, DeAngelis LM, Blakeley J, et al. Corticosteroid use endpoints in neuro-oncology: Response Assessment in Neuro-Oncology Working Group. NeuroOncol. 2018;20(7):897-906. https://doi.org/10.1093/neuonc/noy056

29. Pitter KL, Tamagno I, Alikhanyan K, Hosni-Ahmed A, Pattwell SS, Donnola S, et al. Corticosteroids compromise survival in glioblastoma. Brain. 2016;139(5):1458-71. https://doi.org/10.1093/brain/ aww046

30. Gilbert MR, Dignam JJ, Armstrong TS, Wefel JS, Blumenthal DT, Vogelbaum MA, et al. A Randomized Trial of Bevacizumab for Newly Diagnosed Glioblastoma. N Engl J Med. 2014;370(8):699-708. https://doi.org/10.1056/NEJMoa1308573

31. Chinot OL, Wick W, Mason W, Henriksson R, Saran F, Nishikawa R, et al. Bevacizumab plus Radiotherapy-Temozolomide for Newly Diagnosed Glioblastoma. N Engl J Med. 2014;370(8): 709-22. https://doi.org/10.1056/NEJMoa1308345

32. Wick W, Chinot OL, Bendszus M, Mason W, Henriksson R, Saran F, et al. Evaluation of pseudoprogression rates and tumor progression patterns in a phase III trial of bevacizumab plus radiotherapy/ temozolomide for newly diagnosed glioblastoma. Neuro-Oncol. 2016;18(10):1434-41. https://doi. org/10.1093/neuonc/now091

33. Kreisl TN, Kim L, Moore K, Duic P, Royce C, Stroud I, et al. Phase II trial of single-agent bevacizumab followed by bevacizumab plus irinotecan at tumor progression in recurrent glioblastoma. J Clin Oncol. 2009;27(5):740-5. https://doi.org/10.1200/JCO.2008.16.3055

34. Clark AJ, Butowski NA, Chang SM, Prados MD, Clarke J, Polley M-YC, et al. Impact of bevacizumab chemotherapy on craniotomy wound healing. J Neurosurg. 2011;114(6):1609-16. https:// doi.org/10.3171/2010.10.JNS101042

35. Castro BA, Aghi MK. Bevacizumab for glioblastoma: current indications, surgical implications, and future directions. J Neurosurg. 2014;37(6):E9. https://doi.org/10.3171/2014.9.FOCUS14516

36. McLendon R, Friedman A, Bigner D, Van Meir EG, Brat DJ, Mastrogianakis GM, et al. Comprehensive genomic characterization defines human glioblastoma genes and core pathways. Nature. 2008; 455(7216):1061-8. https://doi.org/10.1038/nature07385

37. Parsons DW, Jones S, Zhang X, Lin JC-H, Leary RJ, Angenendt P, et al. An integrated genomic analysis of human glioblastoma multiforme. Science. 2008;321(5897):1807-12. https://doi.org/10.1126/ science. 1164382 
38. Verhaak RGW, Hoadley KA, Purdom E, Wang V, Qi Y, Wilkerson MD, et al. Integrated genomic analysis identifies clinically relevant subtypes of glioblastoma characterized by abnormalities in PDGFRA, IDH1, EGFR, and NF1. Cancer Cell. 2010;17(1):98-110. https://doi.org/10.1016/j. ccr.2009.12.020

39. Goodenberger ML, Jenkins RB. Genetics of adult glioma. Cancer Genet. 2012;205(12):613-21. https://doi.org/10.1016/j.cancergen.2012.10.009

40. Frattini V, Trifonov V, Chan JM, Castano A, Lia M, Abate F, et al. The integrated landscape of driver genomic alterations in glioblastoma. Nat Genet. 2013;45(10):1141-9. https://doi.org/10.1038/ ng. 2734

41. Brennan CW, McKenna A, Campos B, Noushmehr H, Salama SR, Zheng S, et al. The Somatic Genomic Landscape of Glioblastoma. Cell. 2013;155(2):462-77. https://doi.org/10.1016/j.cell.2013.09.034

42. Sturm D, Bender S, Jones DTW, Lichter P, Grill J, Becher O, et al. Paediatric and adult glioblastoma: multiform (epi)genomic culprits emerge. Nat Rev Cancer. 2014;14(2):92-107. https://doi. org/10.1038/nrc3655

43. Shen Y, Grisdale CJ, Islam SA, Bose P, Lever J, Zhao EY, et al. Comprehensive genomic profiling of glioblastoma tumors, BTICs, and xenografts reveals stability and adaptation to growth environments. Proc Natl Acad Sci USA. 2019;116(38):19098-108. https://doi.org/10.1073/pnas.1813495116

44. Shai R, Shi T, Kremen TJ, Horvath S, Liau LM, Cloughesy TF, et al. Gene expression profiling identifies molecular subtypes of gliomas. Oncogene. 2003;22(31):4918-23. https://doi.org/10.1038/ sj.onc. 1206753

45. Liang Y, Diehn M, Watson N, Bollen AW, Aldape KD, Nicholas MK, et al. Gene expression profiling reveals molecularly and clinically distinct subtypes of glioblastoma multiforme. Proc Natl Acad Sci USA. 2005;102(16):5814-9. https://doi.org/10.1073/pnas.0402870102

46. Tso C-L, Freije WA, Day A, Chen Z, Merriman B, Perlina A, et al. Distinct transcription profiles of primary and secondary glioblastoma subgroups. Cancer Res. 2006;66(1):159-67. https://doi. org/10.1158/0008-5472.CAN-05-0077

47. Sun J, Gong X, Purow B, Zhao Z. Uncovering MicroRNA and Transcription Factor Mediated Regulatory Networks in Glioblastoma. PLoS Comp Biol. 2012;8(7):e1002488. https://doi.org/10.1371/journal. pcbi. 1002488

48. Patel AP, Tirosh I, Trombetta JJ, Shalek AK, Gillespie SM, Wakimoto H, et al. Single-cell RNA-seq highlights intratumoral heterogeneity in primary glioblastoma. Science. 2014;344(6190):1396-401. https://doi.org/10.1126/science.1254257

49. Ceccarelli M, Barthel FP, Malta TM, Sabedot TS, Salama SR, Murray BA, et al. Molecular Profiling Reveals Biologically Discrete Subsets and Pathways of Progression in Diffuse Glioma. Cell. 2016;164(3):550-63. https://doi.org/10.1016/j.cell.2015.12.028

50. Darmanis S, Sloan SA, Croote D, Mignardi M, Chernikova S, Samghababi P, et al. Single-Cell RNASeq Analysis of Infiltrating Neoplastic Cells at the Migrating Front of Human Glioblastoma. Cell Rep. 2017;21(5):1399-410. https://doi.org/10.1016/j.celrep.2017.10.030

51. Mack SC, Singh I, Wang X, Hirsch R, Wu Q, Villagomez R, et al. Chromatin landscapes reveal developmentally encoded transcriptional states that define human glioblastoma. J Exp Med. 2019;216(5):1071-90. https://doi.org/10.1084/jem.20190196

52. Li X, Wu C, Chen N, Gu H, Yen A, Cao L, et al. PI3K/Akt/mTOR signaling pathway and targeted therapy for glioblastoma. Oncotarget. 2016;7(22):33440-50. https://doi.org/10.18632/oncotarget.7961

53. Majewska E, Szeliga M. AKT/GSK3ß Signaling in Glioblastoma. Neurochem Res. 2017;42(3):918-24. https://doi.org/10.1007/s11064-016-2044-4

54. Touat M, Idbaih A, Sanson M, Ligon KL. Glioblastoma targeted therapy: updated approaches from recent biological insights. Ann Oncol. 2017;28(7):1457-72. https://doi.org/10.1093/annonc/ mdx 106

55. Mahajan-Thakur S, Bien-Möller S, Marx S, Schroeder H, Rauch BH. Sphingosine 1-phosphate (S1P) signaling in glioblastoma multiforme-A systematic review. Int J Mol Sci. 2017;18(11):2448. https:// doi.org/10.3390/ijms18112448

56. Randall LO. Lipid Composition of Intracranial Tumors. Am J Cancer. 1940;38(1):92-4.

57. Gopal K, Grossi E, Paoletti P, Usardi M. Lipid Composition of Human Intracranial Tumors: A Biochemical Study. Acta Neurochir. 1963;11(2):333-47. https://doi.org/10.1007/BF01402012 
58. Guo D, Prins RM, Dang J, Kuga D, Iwanami A, Soto H, et al. EGFR signaling through an Akt-SREBP-1dependent, rapamycin-resistant pathway sensitizes glioblastomas to antilipogenic therapy. Sci Signal. 2009;2(101):ra82-2. https://doi.org/10.1126/scisignal.2000446

59. Geng F, Guo D. Lipid droplets, potential biomarker and metabolic target in glioblastoma. Intern Med Rev (Wash D C). 2017;3(5). https://doi.org/10.18103/imr.v3i5.443

60. Taïb B, Aboussalah AM, Moniruzzaman M, Chen S, Haughey NJ, Kim SF, et al. Lipid accumulation and oxidation in glioblastoma multiforme. Sci Rep. 2019;9(1):19593-14. https://doi.org/10.1038/ s41598-019-55985-z

61. Gimple RC, Kidwell RL, Kim LJY, Sun T, Gromovsky AD, Wu Q, et al. Glioma Stem Cell-Specific Superenhancer Promotes Polyunsaturated Fatty-Acid Synthesis to Support EGFR Signaling. Can Discov. 2019;9(9):1248-67. https://doi.org/10.1158/2159-8290.CD-19-0061

62. Moberger G, Ringertz N, Hakanson E. Study in nucleic acid metabolism in gliomas. Acta Unio Int Contra Cancrum. 1952;8(2):591-4

63. Bardot V, Dutrillaux AM, Delattre JY, Vega F, Poisson M, Dutrillaux B, et al. Purine and pyrimidine metabolism in human gliomas: relation to chromosomal aberrations. Br J Cancer. 1994;70(2):212-8. https://doi.org/10.1038/bjc.1994.282

64. Wang X, Yang K, Xie Q, Wu Q, Mack SC, Shi Y, et al. Purine synthesis promotes maintenance of brain tumor initiating cells in glioma. Nat Neurosci. 2017;20(5):661-73. https://doi.org/10.1038/ nn. 4537

65. Kofuji S, Hirayama A, Eberhardt AO, Kawaguchi R, Sugiura Y, Sampetrean O, et al. IMP dehydrogenase-2 drives aberrant nucleolar activity and promotes tumorigenesis in glioblastoma. Nat Cell Biol. 2019;21(8):1-18. https://doi.org/10.1038/s41556-019-0363-9

66. Chinnaiyan P, Kensicki E, Bloom G, Prabhu A, Sarcar B, Kahali S, et al. The Metabolomic Signature of Malignant Glioma Reflects Accelerated Anabolic Metabolism. Cancer Res. 2012;72(22):5878-88. https://doi.org/10.1158/0008-5472.CAN-12-1572-T

67. Strickland M, Stoll EA. Metabolic Reprogramming in Glioma. Front Cell Dev Biol. 2017;5:43. https:// doi.org/10.3389/fcell.2017.00043

68. Kofuji S, Sasaki AT. GTP Metabolic Reprogramming by IMPDH2: Unlocking Cancer Cells' Fueling Mechanism. J Biochem. 2020;168(4):319-328. https://doi.org/10.1093/jb/mvaa085

69. Zhou W, Wahl DR. Metabolic Abnormalities in Glioblastoma and Metabolic Strategies to Overcome Treatment Resistance. Cancers. 2019;11(9):1231. https://doi.org/10.3390/cancers11091231

70. Bi J, Chowdhry S, Wu S, Zhang W, Masui K, Mischel PS. Altered cellular metabolism in gliomas - an emerging landscape of actionable co-dependency targets. Nat Rev Cancer. 2020;20(1):57-70. https:// doi.org/10.1038/s41568-019-0226-5

71. Koumenis C, Hammond E, Giaccia A. Tumor microenvironment and cellular stress: signaling, metabolism, imaging, and therapeutic targets. Adv Exp Med Biol. 2014;772:v-viii. https://doi. org/10.1007/978-1-4614-5915-6

72. Neelsen KJ, Zanini IMY, Herrador R, Lopes M. Oncogenes induce genotoxic stress by mitotic processing of unusual replication intermediates. J Cell Biol. 2013;200(6):699-708. https://doi.org/10.1083/ jcb.201212058

73. Bartkova J, Hamerlik P, Stockhausen M-T, Ehrmann J, Hlobilkova A, Laursen H, et al. Replication stress and oxidative damage contribute to aberrant constitutive activation of DNA damage signalling in human gliomas. Oncogene. 2010;29(36):5095-102. https://doi.org/10.1038/onc.2010.249

74. Dasgupta B, Chhipa RR. Evolving Lessons on the Complex Role of AMPK in Normal Physiology and Cancer. Trends Pharmacol Sci. 2016;37(3):192-206. https://doi.org/10.1016/j.tips.2015.11.007

75. Hardie DG. AMP-activated protein kinase: maintaining energy homeostasis at the cellular and whole-body levels. Annu Rev Nutr. 2014;34(1):31-55. https://doi.org/10.1146/ annurev-nutr-071812-161148

76. Guo D, Hildebrandt IJ, Prins RM, Soto H, Mazzotta MM, Dang J, et al. The AMPK agonist AICAR inhibits the growth of EGFRvIII-expressing glioblastomas by inhibiting lipogenesis. Proc Natl Acad Sci USA. 2009;106(31):12932-7. https://doi.org/10.1073/pnas.0906606106

77. Laderoute KR, Amin K, Calaoagan JM, Knapp M, Le T, Orduna J, et al. 5'-AMP-Activated Protein Kinase (AMPK) Is Induced by Low-Oxygen and Glucose Deprivation Conditions Found in Solid-Tumor Microenvironments. Mol Cell Biol. 2006;26(14):5336-47. https://doi.org/10.1128/MCB.00166-06 
78. Liu X, Chhipa RR, Pooya S, Wortman M, Yachyshin S, Chow LML, et al. Discrete mechanisms of mTOR and cell cycle regulation by AMPK agonists independent of AMPK. Proc Natl Acad Sci USA. 2014;111(4):E435-44. https://doi.org/10.1073/pnas.1311121111

79. Chhipa RR, Fan Q, Anderson J, Muraleedharan R, Huang Y, Ciraolo G, et al. AMP kinase promotes glioblastoma bioenergetics and tumour growth. Nat Cell Biol. 2018;20(7):823-35. https://doi. org/10.1038/s41556-018-0126-z

80. Jang T, Calaoagan JM, Kwon E, Samuelsson S, Recht L, Laderoute KR. 5'-AMP-activated protein kinase activity is elevated early during primary brain tumor development in the rat. Int J Cancer. 2011;128(9):2230-9. https://doi.org/10.1002/ijc.25558

81. Rios M, Foretz M, Viollet B, Prieto A, Fraga M, Costoya JA, et al. AMPK Activation by Oncogenesis Is Required to Maintain Cancer Cell Proliferation in Astrocytic Tumors. Cancer Res. 2013 15;73(8): 2628-38. https://doi.org/10.1158/0008-5472.CAN-12-0861

82. Rios M, Foretz M, Viollet B, Prieto A, Fraga M, García-Caballero T, et al. Lipoprotein internalisation induced by oncogenic AMPK activation is essential to maintain glioblastoma cell growth. Eur J Cancer. 2014;50(18):3187-97. https://doi.org/10.1016/j.ejca.2014.09.014

83. Taylor MA, Das BC, Ray SK. Targeting autophagy for combating chemoresistance and radioresistance in glioblastoma. Apoptosis. 2018;23(11-12):563-75. https://doi.org/10.1007/s10495-018-1480-9

84. Huang T, Kim CK, Alvarez AA, Pangeni RP, Wan X, Song X, et al. MST4 Phosphorylation of ATG4B Regulates Autophagic Activity, Tumorigenicity, and Radioresistance in Glioblastoma. Cancer Cell. 2017;32(6):840-8. https://doi.org/10.1016/j.ccell.2017.11.005

85. Chaachouay H, Ohneseit P, Toulany M, Kehlbach R, Multhoff G, Rodemann HP. Autophagy contributes to resistance of tumor cells to ionizing radiation. Radiother Oncol. 2011;99(3):287-92. https:// doi.org/10.1016/j.radonc.2011.06.002

86. Kim W, Lee S, Seo D, Kim D, Kim K, Kim E, et al. Cellular Stress Responses in Radiotherapy. Cells. 2019;8(9):1105. https://doi.org/10.3390/cells8091105

87. Lomonaco SL, Finniss S, Xiang C, Decarvalho A, Umansky F, Kalkanis SN, et al. The induction of autophagy by gamma-radiation contributes to the radioresistance of glioma stem cells. Int J Cancer. 2009;125(3):717-22. https://doi.org/10.1002/ijc.24402

88. Jin H, Gao S, Guo H, Ren S, Ji F, Liu Z, et al. Re-sensitization of radiation resistant colorectal cancer cells to radiation through inhibition of AMPK pathway. Oncol Lett. 2016;11(5):3197-201. https:// doi.org/10.3892/ol.2016.4339

89. Dowling RJO, Zakikhani M, Fantus IG, Pollak M, Sonenberg N. Metformin inhibits mammalian target of rapamycin-dependent translation initiation in breast cancer cells. Cancer Res. 2007;67(22): 10804-12. https://doi.org/10.1158/0008-5472.CAN-07-2310

90. Huang X, Wullschleger S, Shpiro N, McGuire VA, Sakamoto K, Woods YL, et al. Important role of the LKBl-AMPK pathway in suppressing tumorigenesis in PTEN-deficient mice. Biochem J. 2008;412(2):211-21. https://doi.org/10.1042/BJ20080557

91. Tang Y-C, Williams BR, Siegel JJ, Amon A. Identification of aneuploidy-selective antiproliferation compounds. Cell. 2011;144(4):499-512. https://doi.org/10.1016/j.cell.2011.01.017

92. Wheaton WW, Weinberg SE, Hamanaka RB, Soberanes S, Sullivan LB, Anso E, et al. Metformin inhibits mitochondrial complex I of cancer cells to reduce tumorigenesis. Elife. 2014;3:e02242. https://doi. org/10.7554/eLife.02242

93. Corton JM, Gillespie JG, Hawley SA, Hardie DG. 5-aminoimidazole-4-carboxamide ribonucleoside. A specific method for activating AMP-activated protein kinase in intact cells? Eur J Biochem. 1995;229(2):558-65. https://doi.org/10.1111/j.1432-1033.1995.tb20498.x

94. Zannella VE, Dal Pra A, Muaddi H, McKee TD, Stapleton S, Sykes J, et al. Reprogramming metabolism with metformin improves tumor oxygenation and radiotherapy response. Clin Cancer Res. 2013;19(24):6741-50. https://doi.org/10.1158/1078-0432.CCR-13-1787

95. Zhang Y, Storr SJ, Johnson K, Green AR, Rakha EA, Ellis IO, et al. Involvement of metformin and AMPK in the radioresponse and prognosis of luminal versus basal-like breast cancer treated with radiotherapy. Oncotarget. 2014;5(24):12936-49. https://doi.org/10.18632/oncotarget.2683

96. Rao M, Gao C, Guo M, Law BYK, Xu Y. Effects of metformin treatment on radiotherapy efficacy in patients with cancer and diabetes: a systematic review and meta-analysis. Cancer Manag Res. 2018;10:4881-90. https://doi.org/10.2147/CMAR.S174535 
97. Shackelford DB, Abt E, Gerken L, Vasquez DS, Seki A, Leblanc M, et al. LKBl inactivation dictates therapeutic response of non-small cell lung cancer to the metabolism drug phenformin. Cancer Cell. 2013;23(2):143-58. https://doi.org/10.1016/j.ccr.2012.12.008

98. Watts RW. Some regulatory and integrative aspects of purine nucleotide biosynthesis and its control: an overview. Adv Enzyme Regul. 1983;21:33-51. https://doi.org/10.1016/0065-2571(83)90007-9

99. Majd N, Sumita K, Yoshino H, Chen D, Terakawa J, Daikoku T, et al. A Review of the Potential Utility of Mycophenolate Mofetil as a Cancer Therapeutic. J Cancer Res. 2014;2014(6):1-12. https://doi. org/10.1155/2014/423401

100. Allsop J, Watts RW. Purine synthesis and salvage in brain and liver. Adv Exp Med Biol. 1984;165 Pt B:21-6. https://doi.org/10.1007/978-1-4757-0390-0_5

101. Seegmiller JE, Rosenbloom FM, Kelley WN. Enzyme Defect Associated with a Sex-Linked Human Neurological Disorder and Excessive Purine Synthesis. Science. 1967;155(3770):1682-4. https://doi. org/10.1126/science.155.3770.1682

102. Nyhan WL. Behavior in the Lesch-Nyhan syndrome. J Autism Child Schizophr. 1976;6(3):235-52. https://doi.org/10.1007/BF01543464

103. Traut T. Physiological concentrations of purines and pyrimidines. Mol Cell Biochem. 1994; 140(1):1-22. https://doi.org/10.1007/BF00928361

104. Sumita K, Lo Y-H, Takeuchi K, Senda M, Kofuji S, Ikeda Y, et al. The Lipid Kinase PI5P4K $\beta$ Is an Intracellular GTP Sensor for Metabolism and Tumorigenesis. Mol Cell. 2016;61(2):187-98. https:// doi.org/10.1016/j.molcel.2015.12.011

105. Takeuchi K, Senda M, Lo Y-H, Kofuji S, Ikeda Y, Sasaki AT, et al. Structural reverse genetics study of the PI5P4K $\beta$-nucleotide complexes reveals the presence of the GTP bioenergetic system in mammalian cells. FEBS J. 2016;283(19):3556-62. https://doi.org/10.1111/febs.13739

106. Naffouje R, Grover P, Yu H, Sendilnathan A, Wolfe K, Majd N, et al. Anti-Tumor Potential of IMP Dehydrogenase Inhibitors: A Century-Long Story. Cancers. 2019;11(9):1346-30. https://doi. org/10.3390/cancers11091346

107. Gangi-Peterson L, Sorscher DH, Reynolds JW, Kepler TB, Mitchell BS. Nucleotide pool imbalance and adenosine deaminase deficiency induce alterations of N-region insertions during V(D)J recombination. J Clin Invest. 1999;103(6):833-41. https://doi.org/10.1172/JCI4320

108. James SJ, Basnakian AG, Miller BJ. In Vitro Folate Deficiency Induces Deoxynucleotide Pool Imbalance, Apoptosis, and Mutagenesis in Chinese Hamster Ovary Cells. Cancer Res. 1994;54(19):5075-80.

109. Meuth M. The Molecular-Basis of Mutations Induced by Deoxyribonucleoside Triphosphate Pool Imbalances in Mammalian-Cells. Exp Cell Res. 1989;181(2):305-16. https://doi.org/10.1016/ 0014-4827(89)90090-6

110. De Serres F. Genetic Consequences of Nucleotide Pool Imbalance. NY, USA: Springer Science \& Business Media; 2012. 523 p.

111. Wan P. Mechanisms of Radiation Resistance in Deinococcus radiodurans Rl Revealed by the Reconstruction of Gene Regulatory Network Using Bayesian Network Approach. J Proteomics Bioinform. 2013;01(S6):1-5. https://doi.org/10.4172/jpb.S6-007

112. Deng W, Yang Y, Gao P, Chen H, Wen W, Sun Q. Radiation-Resistant Micrococcus luteus SC1204 and Its Proteomics Change Upon Gamma Irradiation. Curr Microbiol. 2016;72(6):767-75. https://doi. org/10.1007/s00284-016-1015-y

113. Valvezan AJ, Turner M, Belaid A, Lam HC, Miller SK, McNamara MC, et al. mTORCl Couples Nucleotide Synthesis to Nucleotide Demand Resulting in a Targetable Metabolic Vulnerability. Cancer Cell. 2017;32(5):624-5. https://doi.org/10.1016/j.ccell.2017.09.013

114. Smit JA, Stark JH. Inhibiting the repair of DNA damage induced by gamma irradiation in rat thymocytes. Radiat Res. 1994;137(1):84-8. https://doi.org/10.2307/3578794

115. Ming M, Zhao B, Qiang L, He Y-Y. Effect of Immunosuppressants Tacrolimus and Mycophenolate Mofetil on the Keratinocyte UVB Response. Photochem Photobiol. 2014;91(1):242-7. https://doi. org/10.1111/php. 12318

116. Zhou W, Yao Y, Scott AJ, Wilder-Romans K, Dresser JJ, Werner CK, et al. Purine metabolism regulates DNA repair and therapy resistance in glioblastoma. Nat. Commun. 2020;11(1):3811-4. https://doi. org/10.1101/2020.03.26.010140 
117. Li H-X, Meng Q-P, Liu W, Li Y-G, Zhang H-M, Bao F-C, et al. IMPDH2 mediate radioresistance and chemoresistance in osteosarcoma cells. Eur Rev Med Pharmacol Sci. 2014 Oct;18(20):3038-44.

118. Carr S, Papp E, Wu J, Natsumeda Y. Characterization of human type I and type II IMP dehydrogenases. J. Biol. Chem. 1993;268(36):27286. https://doi.org/10.1016/S0021-9258(19) 74247-1

119. Dehghani F, Sayan M, Conrad A, Evers J, Ghadban C, Blaheta R, et al. Inhibition of microglial and astrocytic inflammatory responses by the immunosuppressant mycophenolate mofetil. Neuropathol Appl Neurobiol. 2010;36(7):598-611. https://doi.org/10.1111/j.1365-2990.2010.01104.x

120. Miljkovic D, Samardzic T, Cvetkovic I, Mostarica Stojkovic M, Trajkovic V. Mycophenolic acid downregulates inducible nitric oxide synthase induction in astrocytes. Glia. 2002;39(3):247-55. https:// doi.org/10.1002/glia.10089

121. Glomsda BA, Blaheta RA, Hailer NP. Inhibition of monocyte/endothelial cell interactions and monocyte adhesion molecule expression by the immunosuppressant mycophenolate mofetil. Spinal Cord. 2003;41(11):610-9. https://doi.org/10.1038/sj.sc.3101512

122. Liao L-X, Song X-M, Wang L-C, Lv H-N, Chen J-F, Liu D, et al. Highly selective inhibition of IMPDH2 provides the basis of antineuroinflammation therapy. Proc Natl Acad Sci USA. 2017;114(29): E5986-94. https://doi.org/10.1073/pnas.1706778114

123. Dhande IS, Zhu Y, Braun MC, Hicks MJ, Wenderfer SE, Doris PA. Mycophenolate mofetil prevents cerebrovascular injury in stroke-prone spontaneously hypertensive rats. Physiol Genomics. 2017;49(3):132-40. https://doi.org/10.1152/physiolgenomics.00110.2016

124. Wu X. Mycophenolic Acid Is a Potent Inhibitor of Angiogenesis. Arterioscler. Thromb. Vasc. Biol. 2006;26(10):2414-6. https://doi.org/10.1161/01.ATV.0000238361.07225.fc

125. Rovira M, Huang W, Yusuff S, Shim JS, Ferrante AA, Liu JO, et al. Chemical screen identifies FDAapproved drugs and target pathways that induce precocious pancreatic endocrine differentiation. Proc Natl Acad Sci USA. 2011;108(48):19264-9. https://doi.org/10.1073/pnas.1113081108

126. Huang Y, Liu Z, Huang H, Liu H, Li L. Effects of mycophenolic acid on endothelial cells. Int. Immunopharmacol. 2005;5(6):1029-39. https://doi.org/10.1016/j.intimp.2005.01.015

127. Domhan S, Muschal S, Schwager C, Morath C, Wirkner U, Ansorge W, et al. Molecular mechanisms of the antiangiogenic and antitumor effects of mycophenolic acid. Mol. Cancer Ther. 2008;7(6): 1656-68. https://doi.org/10.1158/1535-7163.MCT-08-0193

128. Koehl GE, Wagner F, Stoeltzing O, Lang SA, Steinbauer M, Schlitt HJ, et al. Mycophenolate Mofetil Inhibits Tumor Growth and Angiogenesis In Vitro but Has Variable Antitumor Effects In Vivo, Possibly Related to Bioavailability. Transplantation. 2007;83(5):607-14. https://doi.org/10.1097/01. tp.0000253756.69243.65

129. Rodríguez-Pascual J, Sha P, García-García E, Rajeshkumar NV, Vicente E, Quijano Y, et al. A preclinical and clinical study of mycophenolate mofetil in pancreatic cancer. Mol Cell Biochem. 2008;316(1-2):57-62.

130. Rodr guez-Pascual J, Sha P, Garcia-Garcia E, Rajeshkumar NV, De Vicente E, Quijano Y, et al. A preclinical and clinical study of mycophenolate mofetil in pancreatic cancer. Invest New Drugs. 2012;31(1):14-9. https://doi.org/10.1007/s10637-012-9822-x

131. Weksler B, Romero IA, Couraud P-O. The hCMEC/D3 cell line as a model of the human blood brain barrier. Fluids Barriers CNS. 2013;10(1):16. https://doi.org/10.1186/2045-8118-10-16

132. Markoutsa E, Pampalakis G, Niarakis A, Romero IA, Weksler B, Couraud P-O, et al. Uptake and permeability studies of BBB-targeting immunoliposomes using the hCMEC/D3 cell line. Eur J Pharm. Biopharm. 2011;77(2):265-74. https://doi.org/10.1016/j.ejpb.2010.11.015

133. Fasler-Kan E, Suenderhauf C, Barteneva N, Poller B, Gygax D, Huwyler J. Cytokine signaling in the human brain capillary endothelial cell line hCMEC/D3. Brain Res. 2010;1354:15-22. https://doi. org/10.1016/j.brainres.2010.07.077

134. Weiss N, Miller F, Cazaubon S, Couraud P-O. The blood-brain barrier in brain homeostasis and neurological diseases. Biochim Biophys Acta Biomembr. 2009;1788(4):842-57. https://doi.org/10.1016/j. bbamem.2008.10.022 
135. Dauchy S, Miller F, Couraud P-O, Weaver RJ, Weksler B, Romero I-A, et al. Expression and transcriptional regulation of $\mathrm{ABC}$ transporters and cytochromes $\mathrm{P} 450$ in hCMEC/D3 human cerebral microvascular endothelial cells. Biochem Pharmacol. 2009;77(5):897-909. https://doi.org/10.1016/j. bcp.2008.11.001

136. Poller B, Gutmann H, Krähenbühl S, Weksler B, Romero I, Couraud P-O, et al. The human brain endothelial cell line hCMEC/D3 as a human blood-brain barrier model for drug transport studies. J Neurochem. 2008;107(5):1358-68. https://doi.org/10.1111/j.1471-4159.2008.05730.x

137. Weksler BB, Subileau EA, Perrière N, Charneau P, Holloway K, Leveque M, et al. Blood-brain barrierspecific properties of a human adult brain endothelial cell line. FASEB J. 2005;19(13):1872-4. https:// doi.org/10.1096/fj.04-3458fje 
